\title{
Substituição do farelo de trigo pelo farelo de sabugo de milho
}

\author{
A. P. TRIVELIN \\ Assistente \\ Escola Superior de Agricultura "Luiz de Queiroz" \\ Universidade de São Paulo
}

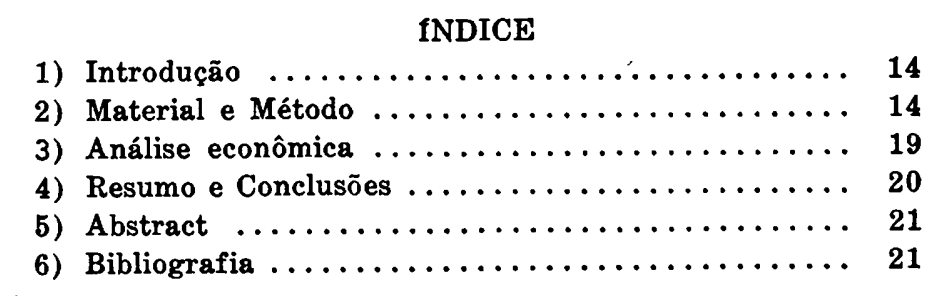

Trabalho da Seção de Avicultura 


\section{1 - INTRODUÇÃO}

Inúmeras são as experiências realizadas procurando substituir determinados alimentos por outros, afim de se observar o aproveitamento da ração pelas aves. Com tal objetivo procurámos também pesquisar o comportamento delas, quando substituido o farelo de trigo, pêso a pêso, pelo farelo de sabugo.

Aquêle alimento, produto resultante da moagem dos grãos de trigos, é reputado por suas qualidades nutritivas e dietéticas, estando " enquadrado entre os alimentos concentrados, em virtude de sua riqueza em proteina $(16 \%)$. Os avicultores atribuem a êsse produto valor demasiado, considerando-o como indispensável na alimentação.

Tendo ocorrido por várias vezes a carência dêsse produto no mercado, resolvemos investigar sua possível substituição pelo farelo de sabugo de milho, embora considerado volumoso por apresentar elevado teor em fibra $(38,9 \%)$, pequena porcentagem de proteina $(3,5 \%)$ e de pouco valor alimentício para as aves, por ser a fibra um nutriente muito pouco assimilável, servindo particularmente como lastro para aumentar o volume da ração.

Assim para efeito de apreciação, procedemos a substituição quantitativa do farelo de trigo pelo de sabugo, cujos resultados e conclusões são relatados neste trabalho.

\section{2 - MATERIAL E METODO}

Reunimos 100 pintos da raça Rhode Island Red, em dois lotes $\mathrm{A}$ e $\mathrm{B}$, os quais estiveram submetidos a raçōes que sòmente se diferençavam pela substituição quantitativa do farelo de trigo pelo farelo de sabugo, como se pode observar no quadro I. Ambos os lotes, durante todo tempo que durou a experiência, estiveram sob as mesmas condições, apenas diferindo naquele particular. 


\section{QUADRO I}

\begin{tabular}{l|c|c}
\hline \multirow{2}{*}{ Ingredientes } & \multicolumn{2}{|c}{ Ração } \\
\cline { 3 - 3 } & A & B \\
\hline Milho & 46 quilos & 46 quilos, \\
Farinha de carne & 12 quilos & 12 quilos \\
Torta de Algodão & 12 quilos & 12 quilos \\
Farelinho de arroz & 10 quilos & 10 quilos \\
Refinazil & 10 quilos & 10 quilos \\
Farelo de trigo & 10 quilos & $\frac{1}{\text { quilos }}$ \\
Farelo de sabugo de milho & - quilos & 10 quilos \\
Ostra & 4 quilos & 4 quilos \\
Sal & 1 quilo & 1 quillo \\
Delsterol & 15 gramas & 15 gramas \\
Sulfato de manganês & 20 gramas & 20 gramas \\
\hline$\%$ de proteina & 20,52 & 19,31 \\
\hline$\%$ de fibras & 5,28 & 8,48 \\
\hline
\end{tabular}

A primeira pesada foi realizada em $29-7-49$, sendo as demais de $7 \mathrm{em} 7$ dias até a sétima, que foi a última na presente experiência.

A ração $B$ foi finamente moida, afim de que os pintos não pudessem escolher os alimentos mais apetecíveis. Sòmente em 20-8-49, ou seja, 21 dias após o início da experiência é que a ração A foi moida, de maneira a apresentar o mesmo grau de finura quando se percebeu essa conveniência. Contudo não atribuimos a êsse fato o maior aumento de pêso do lote $A$, uma vez que a diferença entre as médias continuou sempre crescente, mesmo em igualdade de condições.

No decurso do trabalho não observámos qualquer anormalidade, que pudéssemos interpretar como sendo resultante da substituição atrás mencionada. Verificámos tão sòmente que o pêso médio do lote $A$, em cuja ração entrou o farelo de trigo, foi sempre superior ao do lote $B$, na qual substituimos aquêle ingrediente pelo farelo de sabugo (quadro II). 


\section{QUADRO II}

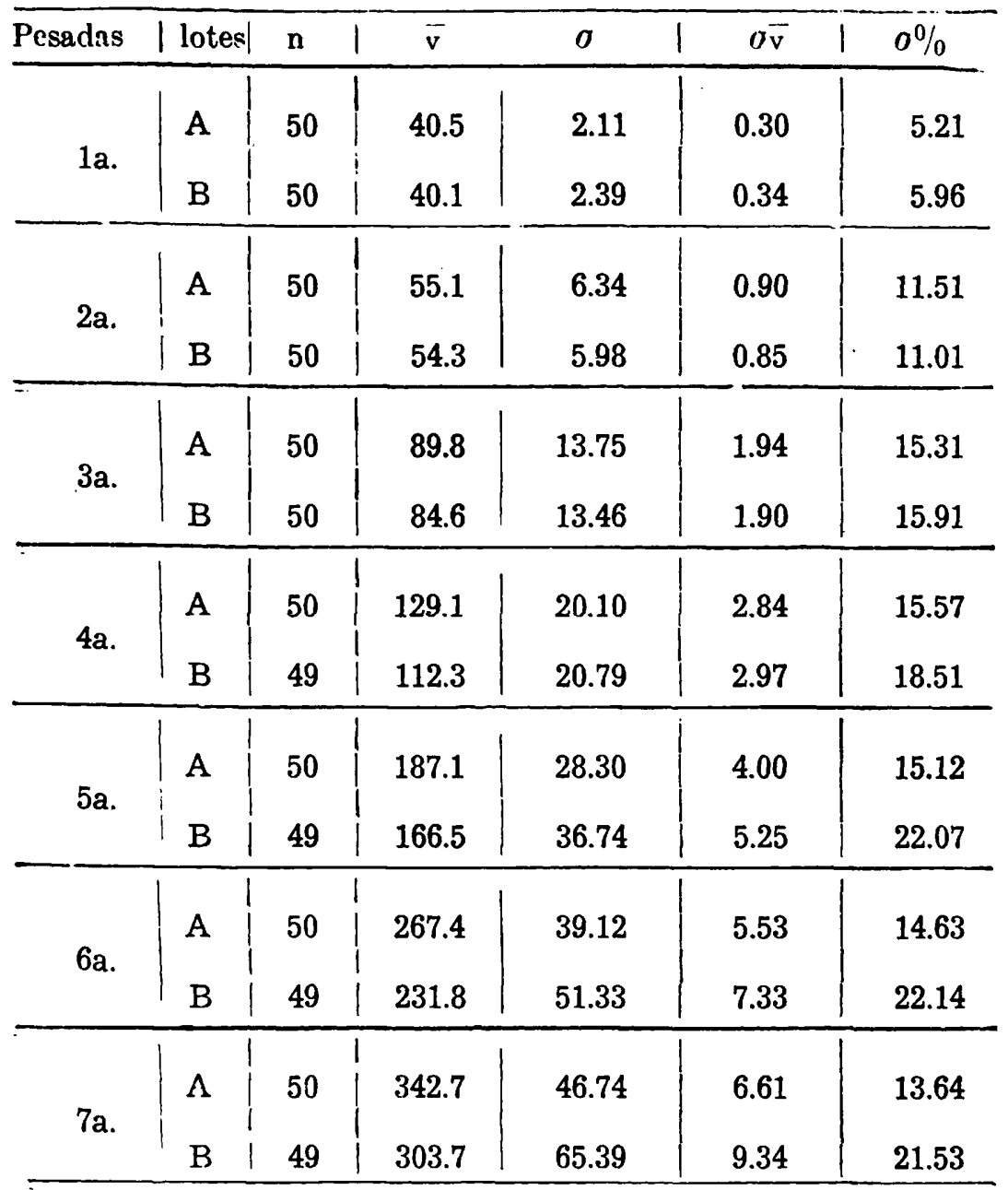

$O$ test $t$ resultante da comparação entre as médias dos lotes A e B, está incluso no quadro III, onde constatámos que até a terceira pesada, foi insignificante a diferença entre elas. $\mathrm{Da}$ quarta em diante, o lote A mostrou-se superior ao lote B, o que vem indicar que aquela substituição redundou em prejuizo. 
QUADRO III

Valores de $\mathrm{t}$

\begin{tabular}{c|c|c|c|c|c|c|c}
\hline & 1a P. & 2a P. & 3a P. & 4a P. & $5 \mathrm{a}$ P. & 6a P. & 7a P. \\
\hline $\mathrm{A} / \mathrm{B}$ & 0.89 & 0.65 & 1.92 & 4.10 & 3.12 & 3.88 & 3.41 \\
& & & \multicolumn{2}{|c|}{ Insignificantes } & \multicolumn{3}{|c}{ Significantes } \\
\hline
\end{tabular}

Como verificámos que alguns pintos apresentavam pesos muito baixos em relação à média, procurámos eliminar essa fonte de variação e procedemos a nova análise. No lote $\mathrm{B}$, fizemos eliminações de duas variáveis - " 58 " e " 76 " - respectivamente da quarta e quinta pesada. Os valores de t 3,93 e 2,94 mostraram significâncias estatísticas entre as médias dos iotes A e B, para aquelas pesadas, confirmando a análise anterior. $\mathrm{Na}$ sexta e sétima, também procedemos a novas eliminações, cujos valores de $t$, inclusos nos quadros V e VII, mostraram-se estatisticamente significantes, o que confirma plenamente a conclusão chegada, de que a ração do lote $\mathrm{A}$ foi superior à do lote $B$.

QUADRO IV

(Sexta Pesada)

\begin{tabular}{|c|c|c|c|c|c|}
\hline Lotes & & $\bar{v}$ & $\sigma$ & $\sigma \overline{\mathrm{v}}$ & $\boldsymbol{\sigma}^{\%} \%$ \\
\hline A & $\begin{array}{r}\text { S/ } \\
\text { Elimin. }\end{array}$ & 267.4 & 39.12 & 5.53 & 14.63 \\
\hline & $\begin{array}{r}\mathrm{S} / \\
\text { Elimin. }\end{array}$ & 231.8 & 51.33 & 7.33 & 22.14 \\
\hline : & $\begin{array}{r}\text { Elimin. } \\
\text { var. } \\
106\end{array}$ & 234.4 & 48.45 & 7.00 & 20.67 \\
\hline & $\begin{array}{l}\text { Elimin. } \\
\text { var. } \\
106+137\end{array}$ & 236.5 & 46.78 & 6.83 & 19.78 \\
\hline
\end{tabular}




\section{QUADRO V}

Valores de $t$

(Sexta Pesada)

\begin{tabular}{|c|c|c|c|}
\hline & $\begin{array}{l}\mathrm{S} / \\
\text { Eliminação }\end{array}$ & $\begin{array}{c}\text { Elimin. } \\
\text { var. } \\
106\end{array}$ & $\begin{array}{c}\text { Elimin. } \\
\text { var. } \\
106+137\end{array}$ \\
\hline \multirow[t]{2}{*}{$A / B$} & 3.88 & 3.70 & 3.52 \\
\hline & \multicolumn{3}{|c|}{ Significantes } \\
\hline
\end{tabular}

QUADRO VI

(Sétima Pesada)

\begin{tabular}{|c|c|c|c|c|c|}
\hline Lotes & & $\bar{v}$ & $\sigma$ & $\sigma_{\bar{v}}$ & $\sigma \%$ \\
\hline A & $\begin{array}{r}S / \\
\text { Elimin. }\end{array}$ & 342.7 & 46.74 & 6.61 & 13.64 \\
\hline \multirow{4}{*}{ B } & Elimin. & 303.7 & 65.39 & 9.34 & 21.53 \\
\hline & $\begin{array}{r}\text { Elimin. } \\
\text { var. } \\
137\end{array}$ & 307.2 & 61.35 & 8.87 & 19.97 \\
\hline & $\begin{array}{c}\text { Elim. } \\
\text { var. } \\
137+168\end{array}$ & 310.1 & 58.44 & 8.53 & 18.85 \\
\hline & $\begin{array}{l}\text { Elimin. } \\
\text { var. } \\
137+168+175\end{array}$ & 313.1 & 55.47 & 8.18 & 17.72 \\
\hline
\end{tabular}




\begin{tabular}{|c|c|c|c|c|}
\hline \multicolumn{5}{|c|}{$\begin{array}{l}\text { QUADRO VII } \\
\text { Valores de } t \\
\text { (Sétima Pesada) }\end{array}$} \\
\hline & $\begin{array}{l}\text { S/ } \\
\text { Elimin. }\end{array}$ & $\begin{array}{l}\text { Elimin. } \\
\text { var. } \\
137\end{array}$ & $\begin{array}{l}\text { Elimin. } \\
\text { var. } \\
137+168\end{array}$ & $\begin{array}{c}\text { Elimin. } \\
\text { var. } \\
137+168+175\end{array}$ \\
\hline \multirow[t]{2}{*}{$A / B$} & 3.41 & 3.21 & 3.02 & 2.82 \\
\hline & \multicolumn{4}{|c|}{ Significantes } \\
\hline
\end{tabular}

Esse aumento de pêso equivalente a $12,8 \%$ do lote $\mathrm{A}$ em relação ao $\mathrm{B}$, poderá ser considerado pequeno na prática, como realmente o é, de 39 gramas em 303,7 gramas, embora estatisticamente, tenha-se revelado significante. $O$ farelo de sabugo de milho perde em todos princípios nutritivos para o farelo de trigo, com exceção feita apenas para as fibras, de modo que a introdução dêsse alimento dará à ração teor mais elevado nesse elemento. Essa substituição total ou parcial poderá ser aconselhada para alimentação de pintos onde se constate manifestações acentuadas de canibalismo, desde que êste farelo entre até a proporção máxima de $10 \%$, que foi a usada em nossa experimentação. Semelhante ração poderá trazer benefícios, visto saber-se que a intensidade dêsse vício é suavizada pelo emprêgo de ração rica em fibras. Assim procedendo, não se espera que o retardamento de crescimento seja superior a $15 \%$, até a idade de 45 dias, como verificámcs.

\section{3 - ANALISE ECONÔMICA}

Economicamente, semelhante substituição não é aconselhável, pois a perda média de pêso de 39 gramas do lote $B$ em relação ao lote $A$, verificado na sétima pesada, traduziu num prejuizo de algumas dezenas de cruzeiros, para um total de 49 aves.

No caso de se encarar essa substituição, visando alimentação de maior número de pintos, êsse prejuizo agravar-se-á ainda mais.

Infelizmente, não registrámos a quantidade de alimento gasto nesta experimentação, de modo que para sua apreciação 
determinámos aproximadamente o pêso do alimento consumido durante os 45 dias, ou seja, até 6 semanas de idade (5). Esse pêso total foi aproximadamente de 100 quilos, sendo 50 quilos fornecidos ao lote B e 50 ao lote A; no lote B tivemos o farelo de sabugo substituindo totalmente o farelo de trigo, entrando na proporção de $10 \%$ do pêso da ração. Disso resulta que no lote $B$, foram gastos sòmente 5 quilos de farelo de sabugo de milho.

Considerando o valor dêste farelo pelo custo de sua moagem ou seja Cr $\$ 0,10$ o quilo, essa substituição determinou pequeno barateamento $(\mathrm{Cr} \$ 3,00)$ da ração $\mathrm{B}$, relativamente a ração $\mathrm{A}$, uma vez que o farelo de trigo alcança o preço de $\mathrm{Cr} \$ 0,70$ o quilo.

Estimando em $\mathrm{Cr} \$ 15,00$ o pêso vivo das aves áquela idade, o lote $A$, cujo pêso total na sétima pesada foi de 17,137 quilos, teve seu valor estimativo calculado em $\mathrm{Cr} \$ 257,06$, enquanto que o $\mathrm{B}$, na mesma pesada, apresentando o pêso total de 14,882 quilos, apenas alcançou $\mathrm{Cr} \$ 223,23$. Disso se deduz um prejuizo de $\operatorname{Cr} \$ 33,83$ auferido do lote $B$, no qual o farelo de sabugo entrou substituindo o farelo de trigo.

Assim concluimos que economicamente não se aconselha a referida substituição, uma vez que o pequeno barateamento do custo da ração trouxe prejuizo correspondente a 11 vezes a diferença de preço alcançado por essas aves áquela idade.

\section{4 - RESUMO E CONCLUSŐES}

Com 100 pintos fêmeas da raça Rhode Island Red formamos dois lotes A e B, os quais durante todo o tempo que durou a experiência estiveram submetidos às mesmas condições experimentais, apenas diferenciando pela substituição quantitativa do farelo de trigo pelo farelo de sabugo de milho (quadro I).

A experiência foi iniciada em 29-7-49 e a partir desta data procedemos a pesadas semanais, até a sétima. Os dados colhidos nestas pesadas e analisadas revelaram que a ração $A$ foi superior à ração $\mathrm{B}$, na qual entrou o farelo de sabugo, substituindo, pêso a pêso, o farelo de trigo. Os valores de $t$, resultantes da comparação entre as médias dos lotes A e B (quadro III) mostraram-se estatisticamente significantes, da quarta pesada em diante. Mesmo eliminando algumas variáveis, que se apresentavam muito inferiores em relação à média, os valores de $t$, foram significantes (quadros V e VII) a partir da referida pesada, o que confirma a conclusão anterior.

Não obstante essa significância estatística, o aumento de pêso do lote $\mathrm{A}$ em relação ao $\mathrm{B}$, que foi de $12,8 \%$, pode ser 
considerado na prática como pequeno. Como nada de anormal foi observado a não ser êsse pequeno aumento de pêso do lote $\mathrm{A}$ em relação ao $\mathrm{B}$, julgamos acertado aconselhar a introdução do farelo de sabugo até a proporção máxima de $10 \%$, que foi a usada em nossa experimentação, em ração destinada a pintos quando se observe manifestações acentuadas de canibalismo. $\mathrm{O}$ farelo de sabugo conferirá à ração maior teor de fibras, o que nos leva a aconselhar o seu emprêgo naquele caso especial, visto saber-se que a intensidade dêsse vício diminui com o emprêgo de ração rica neste elemento.

Nestas condições o retardamento de crescimento é possivel que não seja superior a $15 \%$, até 45 dias de idade, como verificámos na presente experiência, onde o farelo de sabugo entrou na proporção máxima de $10 \%$.

Economicamente, semelhante substituição não é aconselhável. Com a introdução do farelo de sabugo, substituindo totalmente o farelo de trigo, tivemos pequeno barateamento .... $(\mathrm{Cr} \$ 3,00)$ do custo da ração, barateamento êste, que redundou num prejuizo equivalente a 11 vezes a diferença de preço alcançado por essas aves, na idade de 45 dias.

\section{ABSTRACT}

Two 50 R. I. R. chicken groups were contrasted, both receiving the same basic-ration differing only in the content of wheat bran or corn cobs meal. One ration had $10 \%$ of wheat bran and in the other one the $10 \%$ of wheat bran has been substituted by $10 \%$ of corn cobs meal.

It was found on the final weight a significant advantage of $12,8 \%$ with wheat bran. However, the development of chikens receiving corn cobs meal was quite normal.

\section{BIBLIOGRAFIA}

1-ATHANASSOF, Nicolau. (1943) - Manual do criador de Bovinos. Ed. Melhoramentos. São Paulo.

2-BRIEGER, F. G. (1937) - Tábuas e fórriulas para estatística. Cia. Melhoramentos. São Paulo.

3-TORRES, A. Di Paravicini. (1949) - Alimentação das Aves - Noções práticas. Ed. Melhoramentos. São Paulo.

4-TORRES, A. Di Paravicini e A. Piedade - Influência do carvão na alimentação das aves. Anais da Esc. Sup. de Agric. "Luiz de Queiroz" - Piracicaba. Vol. 3, 1946.

5-WAITE, Roy H. (1929) - Poultry Science and Practice New York. 
